\title{
Study on China Regional Innovation Efficiency of One Belt and One Road
}

\author{
Xingneng Xia ${ }^{1}$, Taozhu Feng ${ }^{2,}$, Xie Zhou ${ }^{2}$ \\ ${ }^{1}$ Management College, Xi'an University of Science and Technology, Xi'an, China \\ ${ }^{2}$ Economic College, Shanghai University, Shanghai, China
}

\section{Email address:}

xiaxingneng@163.com (Xingneng Xia),876314690@qq.com (Taozhu Feng),1746553175@qq.com (Xie Zhou)

${ }^{*}$ Corresponding author

\section{To cite this article:}

Xingneng Xia, Taozhu Feng, Xie Zhou. Study on China Regional Innovation Efficiency of One Belt and One Road. Science Innovation. Vol. 5, No. 4, 2017, pp. 238-244. doi: 10.11648/j.si.20170504.18

Received: April 6, 2017; Accepted: May 5, 2017; Published: May 11, 2017

\begin{abstract}
This paper divides technology innovation into knowledge-output phase and commercialization phase, using the panel data of the "one belt and one road" from 2010 to 2014. And also it measures the technology innovation efficiency during the two phases based on DEA and malmquist index. Meanwhile, we make the quantitative adjustment of the input and output index of the two phases. the results shows as follows: The technical efficiency is generally lower in the knowledge-output phase compared to the commercialization phase. Scale efficiency is the main cause of restricting the improvement of technical efficiency of $21^{\text {st }}$ century Maritime Silk Road, while pure technical efficiency is the main cause of technical efficiency of the Silk Road Economic Belt. The growth of TFP generally comes from the technical progress. Technical efficiency has a lager potential growth to improve. Finally, for the above-mentioned problems, we give the corresponding policy suggestions.
\end{abstract}

Keywords: One Belt and One Road, Technology Innovation, Pure Technical Efficiency, Scale Efficiency, DEA, TFP

\section{中国“一带一路”沿线地区技术创新效率研究}

夏兴能 ${ }^{1}$, 冯套柱 $^{2 *}$, 周监 ${ }^{2}$

1管理学院, 西安科技大学, 西安, 中国

${ }^{2}$ 经济学院, 上海大学, 上海, 中国

邮箱

xiaxingneng@163.com（夏兴能），876314690@qq. com（冯套柱），1746553175@qq. com（周焞）

摘要：将技术创新分为技术知识产出阶段和技术商业化阶段。运用DEA和Malmquist指数法，测度2010-2014年中国 “一 带一路” 沿线地区技术创新效率情况, 对改善其投入与产出要素作出定量调整。研究结果表明: 沿线地区在技术知识 产出阶段技术效率水平较低，在技术商业化阶段技术效率水平较高; 规模效率是制约中国 “海上丝路” 地区技术效率 提高的主要原因，纯技术效率是制约我国 “丝绸经济带” 地区技术效率提高的主要因素; 中国 “一带一路” 沿线地区 TFP呈增长态势，主要贡献来于技术进步，技术效率有较大提升潜力。最后基于这些问题给出了相应的政策建议。

关键词: 一带一路, 技术创新, 纯技术效率, 规模效率, DEA, TFP 


\section{1. 引言}

科学技术是第一生产力, 经济发展与技术创新紧密相 关, 加强区域发展联动和技术创新效率是实施“一带一路” 战略的重要举措。研究我国 “一带一路” 沿线地区技术创 新效率, 提高技术创新能力, 对我国在与 “一带一路” 沿 线国家经济技术发展互动中处于主动地位具有重要意义。

\section{2. 相关文献评述}

刘卫东 [1] 从地缘政治以及空间内涵的角度阐述了 “一带一路” 战略对于经济全球化和世界格局的影响。吴 建南、杨若愚 [2]从中国与 “一带一路” 国家合作论文的 特征出发, 分析各国的论文数量与研究领域等差异, 得出 各国之间要相互加强科技合作的结论。孔庆峰、董虹蔚 [3] 通过构建贸易便利化指标体系以及引力模型对 “一带一路” 沿线69个国家的贸易便利化水平进行了测算。杨广青、杜 海鹏 [4]对 “一带一路” 沿线国家出口贸易与人民币汇率 变动的关系作了相关研究。张良为 [5] 以广东省为例, 从 自贸区视角对 “一带一路” 战略下国际物流与国际贸易的 协同关系进行了分析。陈恒、魏修建 [6]等基于劳动力投 入视角对“一带一路”物流业发展的演变轨迹进行了研究。 Jooh Lee\&Eunsup Shim[7]、Romi jn [8]、Nee1-ankavi1 [9] 等对高技术产业创新效率进行了研究。赵树宽 [10]、熊婵 [11]等研究了高技术企业的效率评价问题并构建了评价 指标体系。Maria[12]、郭军华等 [13]、官建成 [14]等对 区域创新效率的评价问题进行了研究。

总之, 关于 “一带一路” 的研究大多集中于宏观层面 和产业层面, 对于技术创新效率等中微观层面的研究较少。 关于技术创新效率的研究文献较多, 但缺乏对我国 “一带 一路” 沿线地区技术创新及效率提高的研究。为此, 本文 利用DEA方法和Malmquist指数探讨我国 “一带一路” 沿线 地区技术创新效率变动情况, 为实施 “一带一路” 战略和 我国沿线地区经济发展提供有用的政策支持和良好导向。

\section{3. 模型与数据}

\section{1. DEA模型}

数据包络分析 (data envelopment analysis, DEA) 方 法是基于投入产出数据的相对有效性评价方法, 是由 Charnes和Cooper等人创建的。目前DEA方法已经成为多投 入多产出情况下决策单元相对有效性和规模收益等方面 应用最为广泛的数理方法之一 [15]。该方法的基本思想起 源于Farrell对现代效率测度 (efficiency measurement) 的研究。效率测度评价方法主要分为参数法和非参数法两 类, 参数法主要以Coel1 $\mathrm{i}$ 等研究的随机前沿生产函数分析 法 (Stochastic Frontier Analysis, SFA) 为代表, 非参 数法则以Charnes, Cooper and Rhodes的数据包络分析法 为代表。与 SFA 等参数法相比, DEA方法具有自如处理多 投入多产出指标的复杂问题, 无需知道生产函数具体形式 等优点。常见的DEA模型有两种。一种是基于固定报酬规
模不变 (Constant Return Scale, CRS) 的CCR模型, 可以 用来衡量被观测的DMU总体效率, 当DMU无效时, 它无法判 断该DMU的无效是由于纯技术效率出现问题还是基于规模 效率出现问题。因而Banker, Charnes和Cooper 提出了基 于规模报酬变动（Variable Return Scale, VRS）假设的 BCC 模型。其模型的具体表述如下:

假设有 $\mathrm{n}$ 个DMU，每个 $D M U_{j}(j=1,2, \ldots, n)$ 都有 $\mathrm{m}$ 种投入指 标和 $\mathrm{s}$ 种产出指标。分别记为投入集合 $x_{i j}(i=1,2, \ldots, m)$, 产 出集合 $y_{r j}(r=1,2, \ldots, s)$ 。根据Banker 定义的生产可能集 (PPS), 定义 $\mathrm{T}=\{(\mathrm{x}, \mathrm{y}) \mid \mathrm{x}$ 为产出量, $\mathrm{y}$ 为投入量 $\}$, 我们可 以得到基于 $\mathrm{BCC}$ 模型的以下约束条件的 PPS: $T=\left\{(x, y) \mid \sum_{j=1}^{n} \lambda_{j} x_{j} \leq x, \sum_{j=1}^{n} \lambda_{j} y_{j} \geq y, \lambda_{j} \geq 0, \sum_{j=1}^{n} \lambda_{j}=1\right\}$, 那么有:

$$
\left\{\begin{array}{l}
\max \theta=\frac{\sum_{r=1}^{S} u_{r} y_{r 0}}{\sum_{i=1}^{m} v_{i} x_{i 0}} \\
\sum_{r=1}^{S} u_{r} y_{r j}-\sum_{i=1}^{m} v_{i} x_{i j} \leq 0, i=1,2, \ldots, n \\
u_{r}, v_{i} \geq \varepsilon, r=1,2, \ldots, s . i=1,2, \ldots, m \\
\sum_{j=1}^{n} \lambda_{j}=1, \lambda_{j} \geq 0
\end{array}\right.
$$

$\varepsilon$ 为非 阿 基米德 无穷小, 令 $\mu_{r}=t u_{r}, v_{i}=t v_{i}, t=\left(\sum_{i=1}^{m} v_{i} x_{i j}\right)^{-1}$, 经过Charnes-Cooper转 换得到带有阿基米德无穷小量的DEA-BCC模型的对偶形式 的包络模型:

$$
\min \theta=\theta^{0}-\varepsilon\left(\sum_{r=1}^{S} s_{r}^{+}+\sum_{i=1}^{m} s_{i}^{-}\right)
$$

$$
\left\{\begin{array}{l}
\sum_{j=1}^{\mathrm{n}} \lambda_{j} x_{i j}+s_{i}{ }^{-}=\theta^{0} x_{i 0} \\
\sum_{j=1}^{n} \lambda_{j} y_{r j}-s_{r}{ }^{+}=y_{r 0} \\
\sum_{j=1}^{n} \lambda_{j}=1, \lambda_{j}, s_{i}^{-}, s_{r}{ }^{+} \geq 0 \\
i=1,2, \ldots, m, r=1,2, \ldots, s, j=1,2, \ldots, n
\end{array}\right.
$$

假设上式存在最优解 $\theta^{0}, \lambda_{j}{ }^{0}, s_{i}^{-0}, s_{r}^{+0}$, 并且满足 $\theta^{0}=1$, $s_{i}^{-0}=0, s_{i}^{+0}=0$, 则称 $D M U_{j_{0}}$ 为DEA有效; 当只满足 $\theta^{0}=1$ 时, 则称 $D M U_{j_{0}}$ 为弱DEA有效, 也就是说该DMU的投入或 者产出存在不足或者过量。当 $\theta^{0} \neq 1$ 时, 则称 $D M U_{j 0}$ 为 DEA 无效。弱DEA有效和DEA无效统称为非DEA有效。 


\section{2. Malmquist指数}

Malmquist指数是由瑞典经济学家Sten Malmquist提 出, Caves、Christensen以及Diewert等人率先将这一指 数用于生产效率的测度, Fare等人将Malmquist指数从理 论指数变成了实证指数。其模型公示如下:

$$
M_{i}\left(x_{i}^{t}, y_{i}^{t}, x_{i}^{t+1}, y_{i}^{t+1}\right)=\left[\frac{D_{i}^{t}\left(x_{i}^{t+1}, y_{i}^{t+1}\right)}{D_{i}^{t}\left(x_{i}^{t}, y_{i}^{t}\right)} \cdot \frac{D_{i}^{t+1}\left(x_{i}^{t+1}, y_{i}^{t+1}\right)}{D_{i}^{t+1}\left(x_{i}^{t}, y_{i}^{t}\right)}\right]^{\frac{1}{2}}
$$

其中 $\left(x_{i}^{t}, y_{i}^{t}\right),\left(x_{i}^{t+1}, y_{i}^{t+1}\right)$ 分别表示第 $i$ 个DMU在 $\mathrm{t}$ 和 $\mathrm{t}+1$ 时期 的投入和产出向量, $D_{i}^{t}, D_{i}^{t+1}$ 分别表示以 $\mathrm{t}$ 时期技术 $T^{t}$ 为 参照的时期 $\mathrm{t}$ 和 $\mathrm{t}+1$ 的距离函数。 $M_{i}$ 表示为第 $i$ 个 DMU的 TFP指数（Total Factor Productivity）。

\section{3. 指标选取与数据来源}

通过梳理以往相关文献发现, 尤其是在区域创新效率 评价方面, 投入指标和产出指标选取大多数都是基于一次 性综合性角度来进行研究, 对于效率测度评价不够深入和 细化。鉴于此, 本文从技术知识产出阶段和技术商业化阶 段两个角度研究我国 “一带一路” 沿线地区科技创新效率 测度情况，指标体系见表1所示。

表1 我国 “一带一路” 沿线地区科技创新效率评价指标体系。

\begin{tabular}{|c|c|c|c|}
\hline 阶段 & 指标类型 & 指标名称 & 变量名称 \\
\hline \multirow{4}{*}{$\begin{array}{l}\text { 知识产 } \\
\text { 出阶段 }\end{array}$} & \multirow{2}{*}{ 产出指标 } & 国外三大机构论文收录数 & Y1 \\
\hline & & 国内专利受理数 & Y2 \\
\hline & \multirow{3}{*}{ 投入指标 } & R\&D人员全时当量 & $\mathrm{X} 1$ \\
\hline & & R\&D经费内部支出 & X2 \\
\hline \multirow{7}{*}{$\begin{array}{l}\text { 商业化 } \\
\text { 阶段 }\end{array}$} & & 技术市场成交额 & Y3 \\
\hline & \multirow[t]{3}{*}{ 产出指标 } & 规模以上企业新产品产值 & Y4 \\
\hline & & 高技术产业总产值 & Y5 \\
\hline & & 规模以上企业新产品开发项目数 & X3 \\
\hline & \multirow{3}{*}{ 投入指标 } & 规模以上企业消化吸收经费 & X4 \\
\hline & & 高技术产业施工项目数 & X5 \\
\hline & & 高技术产业企业数 & X6 \\
\hline
\end{tabular}

本文研究所用数据均来自于 《中国科技统计年鉴》 （2011－2015）。由于2011年前统计年鉴中并没有列入规 模以上企业的相关数据, 鉴于规模以上企业和大中型企业 的定义的相似性, 本文用规模以上企业的相关数据来代替。 此外, 由于西藏自治区数据缺失较多, 为了保证结果客观 性和避免由于数据缺失而导致运算失败, 本文选取 “一带 一路”沿线除西藏之外的 17 个省 (市、自治区) 作为样本。

\section{4. 实证结果与分析}

\section{1. 基于DEA的 “一带一路” 沿线地区技术创新效率静态 评价}

利用DEAP2. 1软件对我国 “一带一路” 沿线地区17个 样本省（市、自治区）2010-2014年技术创新效率进行测 度; 按照技术知识产出和技术商业化两个阶段将被测DMU 的相关投入和产出数据代入 $\mathrm{BCC}$ 模型, 基于投入导向角度, 采用多阶段算法对模型进行数据处理, 测算出被测DMU的
综合技术效率、纯技术效率以及规模效率情况, 并且得到 了各项投入指标的穴余与产出指标的不足等相关情况。

\subsection{1. “一带一路” 沿线地区技术创新效率分析}

从综合技术效率、纯技术效率和规模效率以及规模报 酬等方面对 “一带一路” 沿线地区技术创新效率进行统计 测度, 结果见表 3 和表 4 。

表2 2010-2014年技术知识产出阶段技术效率及规模报酬情况。

\begin{tabular}{llllll}
\hline & & 综合技术效率 & 纯技术效率 & 规模效率 & 规模报酬 \\
\hline 海 & 上海 & 1 & 1 & 1 & 不变 \\
上 & 福建 & 0.596 & 0.609 & 0.979 & 递减 \\
丝 & 广东 & 0.791 & 1 & 0.791 & 递减 \\
路 & 浙江 & 1 & 1 & 1 & 不变 \\
& 海南 & 0.611 & 1 & 0.611 & 递增 \\
& 新疆 & 0.581 & 0.633 & 0.918 & 递增 \\
& 重庆 & 1 & 1 & 1 & 不变 \\
& 陕西 & 0.998 & 1 & 0.998 & 递减 \\
丝 & 甘肃 & 1 & 1 & 1 & 不变 \\
绸 & 宁夏 & 0.264 & 0.365 & 0.723 & 递增 \\
经 & 内海 & 0.283 & 1 & 0.283 & 递增 \\
济 & 内蒙古 & 0.201 & 0.205 & 0.983 & 递增 \\
带 & 黑龙江 & 0.889 & 1 & 0.889 & 递减 \\
& 吉林 & 0.961 & 1 & 0.961 & 递减 \\
& 辽宁 & 0.779 & 0.780 & 0.999 & 递增 \\
& 广西 & 0.423 & 0.426 & 0.992 & 递增 \\
& 云南 & 0.674 & 0.693 & 0.973 & 递增 \\
平均值 & 0.709 & 0.807 & 0.888 & \\
\hline & & & & & \\
\hline
\end{tabular}

表3 2010-2014年技术商业化阶段技术效率及规模报酬情况。

\begin{tabular}{|c|c|c|c|c|c|}
\hline & & 综合技术效率 & 纯技术效率 & 规模效率 & 规模报酬 \\
\hline \multirow{5}{*}{$\begin{array}{l}\text { 海 } \\
\text { 上 } \\
\text { 丝 } \\
\text { 路 }\end{array}$} & 上海 & 1 & 1 & 1 & 不变 \\
\hline & 福建 & 0.979 & 0.986 & 0.993 & 递增 \\
\hline & 广东 & 1 & 1 & 1 & 不变 \\
\hline & 浙江 & 0.761 & 0.913 & 0.833 & 递减 \\
\hline & 海南 & 0.691 & 1 & 0.691 & 递增 \\
\hline \multirow{12}{*}{$\begin{array}{l}\text { 丝 } \\
\text { 绸 } \\
\text { 经 } \\
\text { 带 }\end{array}$} & 新疆 & 0.967 & 1 & 0.967 & 递增 \\
\hline & 重庆 & 1 & 1 & 1 & 不变 \\
\hline & 陕西 & 1 & 1 & 1 & 不变 \\
\hline & 甘肃 & 1 & 1 & 1 & 不变 \\
\hline & 宁夏 & 0.907 & 1 & 0.907 & 递增 \\
\hline & 青海 & 1 & 1 & 1 & 不变 \\
\hline & 内蒙古 & 0.888 & 0.929 & 0.956 & 递增 \\
\hline & 黑龙江 & 0.813 & 0.856 & 0.950 & 递减 \\
\hline & 吉林 & 1 & 1 & 1 & 不变 \\
\hline & 辽宁 & 0.793 & 0.889 & 0.891 & 递减 \\
\hline & 广西 & 0.961 & 1 & 0.961 & 递增 \\
\hline & 云南 & 0.459 & 0.492 & 0.934 & 递增 \\
\hline \multicolumn{2}{|c|}{ 平均值 } & 0.895 & 0.945 & 0.946 & \\
\hline
\end{tabular}

（1）不同阶段情况。在技术知识产出阶段，综合技 术效率的全线均值为 0.709 , 低于 0.5 的地区有 4 个。纯技 术效率的全线均值为 0.807 , 低于 0.85 的有 7 个。规模效率 的全线均值为 0.888 。在技术商业化阶段, 综合技术效率 全线均值为 0.895 , 只有一个地区低于 0.5 。纯技术效率全 线均值为 0.945 , 除了云南, 其余均在 0.85 以上; 规模效 率的全线均值为 0.946 。与技术知识产出阶段相比, 技术 商业化阶段的综合技术效率更高, 技术知识产出阶段的纯 技术效率和规模效率都有较大提升空间, 纯技术效率的提 升潜力更大。 
（2）不同地区情况。“海上丝路”地区在技术知识 产出阶段和技术商业化阶段的纯技术效率都较高, 但是综 合技术效率却偏低, 主要原因是规模效率偏低导致的, 特 别是海南省在两个阶段的纯技术效率都达到了 1 , 但是规 模效率分别只有 0.611 和 0.691 , 海南省的投入产出规模不 合理; “丝绸经济带” 地区在技术知识产出阶段的纯技术 效率较低, 在技术商业化阶段较高, 两个阶段的规模效率 都很高, 拉低该地区综合技术效率的主要因素是纯技术效 率偏低。特别是宁夏、内蒙古和广西在技术知识产出阶段 的纯技术效率分别只有 $0.365 、 0.205$ 和 0.426 , 需要提高 该阶段的研发效率和资源利用率。

（3）规模报酬变动情况。规模报酬不变表示要素的 投入产出规模合理, 递减和递增分别表示投入圥余和不足, 需要适当减少和增加相关投入。在技术知识产出阶段, 上 海、浙江、重庆和甘肃规模报酬不变, 福建、广东、陕西、
黑龙江和吉林规模报酬递减，其余地区规模报酬递增。在 技术商业化阶段，规模报酬不变的地区有上海、广东、重 庆、陕西、甘肃和吉林，规模报酬递减的有浙江、黑龙江 和辽宁, 其余地区处于规模递增。总的来说, “海上丝路” 地区, 除了海南需要适当加大投入，其他地区需要控制现 有规模甚至适当减少规模。“丝绸经济带”地区，除了黑 龙江和吉林需要减少投入, 其他地区需要保持甚至适当增 加当前规模, 特别是加大在技术知识产出阶段的投入力度。

\section{1. 2. 各地区非DEA有效的原因及投入与产出指标调整分 析}

表5、表6分别是DMU在技术知识产出阶段和技术商业 化阶段非DEA有效的原因及投入与产出指标需要调整的具 体数值。

表4 2010-2014年各DMU在技术知识产出阶段非DEA有效的原因。

\begin{tabular}{|c|c|c|c|c|c|}
\hline \multirow[b]{2}{*}{ 非DEA有效地区 } & \multirow[b]{2}{*}{ 综合技术效率 } & \multicolumn{2}{|l|}{ 投入圥余部分 } & \multicolumn{2}{|l|}{ 产出不足部分 } \\
\hline & & R\&D人员全时当量 (万人/年) & R\&D经费内部支出 (万元) & 三大机构论文收录数（篇） & 国内专利受理数 (个) \\
\hline 上海 & 0.596 & 1611.49 & 35888.63 & 2517.56 & 14107.29 \\
\hline 广东 & 0.791 & 72040.59 & 1690282.82 & 0 & 0 \\
\hline 海南 & 0.611 & -1903.42 & -27309.16 & 0 & 0 \\
\hline 新疆 & 0.581 & -1179.30 & -21856.72 & 295.86 & 2065.23 \\
\hline 陕西 & 0.998 & 146.44 & 4350.08 & 0 & 0 \\
\hline 宁夏 & 0.264 & -1766.62 & -31883.06 & 196. 99 & 1285.85 \\
\hline 青海 & 0.283 & -3483.47 & -71296.97 & 0 & 0 \\
\hline 内蒙古 & 0.201 & -421.01 & -10832.49 & 1706.85 & 11321.94 \\
\hline 黑龙江 & 0.889 & 6865.83 & 136578. 15 & 0 & 0 \\
\hline 吉林 & 0.961 & 1767.21 & 29562.19 & 0 & 0 \\
\hline 辽宁 & 0.779 & -84.65 & -287.47 & 3137. 11 & 9667.60 \\
\hline 广西 & 0.423 & -271.89 & -5029.57 & 1689.82 & 6889.88 \\
\hline 云南 & 0.674 & -608.89 & -11925.14 & 636.80 & 2499.83 \\
\hline
\end{tabular}

表5 2010-2014年各DMU在商业化阶段非DEA有效的原因。

\begin{tabular}{|c|c|c|c|c|c|c|c|c|}
\hline \multirow{3}{*}{$\begin{array}{l}\text { 非DEA有 } \\
\text { 效地区 }\end{array}$} & \multirow{3}{*}{$\begin{array}{l}\text { 综合技术 } \\
\text { 效率值 }\end{array}$} & \multicolumn{4}{|l|}{ 投入圥余部分 } & \multicolumn{3}{|l|}{ 产出不足部分 } \\
\hline & & 规模以上企业新产 & 规模以上企业消化 & 高技术产业施 & 高技术产业 & 技术市场成 & 规模以上企业新 & 高技术产业总 \\
\hline & & 品开发项目数 (个) & 吸收经费（万元） & 工项目数 (个) & 企业数 (个) & 交额（万元） & 产品产值 (万元) & 产值（万元） \\
\hline 福建 & 0.979 & -25.96 & -168.18 & -35.44 & -5.54 & 219824.52 & 307499.21 & 37.33 \\
\hline 浙江 & 0.761 & 2311.61 & 17689.98 & 133. 44 & 353.10 & 1676422.6 & 6255184.39 & 7642.77 \\
\hline 海南 & 0.691 & -70.45 & -539.21 & -3.71 & -17.61 & 0 & 0 & 0 \\
\hline 新疆 & 0.967 & -12.34 & -95.14 & -0.86 & -1.12 & 0 & 0 & 0 \\
\hline 宁夏 & 0.907 & -52.73 & -779.71 & -1.12 & -1.49 & 0 & 0 & 0 \\
\hline 内蒙古 & 0.888 & -41.19 & -976.98 & -16.51 & -4.71 & 20763.59 & 464131. 13 & 17.98 \\
\hline 黑龙江 & 0.813 & 2058.05 & 1928.00 & 119.79 & 9.95 & 88849.67 & 999569.7 & 454.76 \\
\hline 辽宁 & 0.793 & 653.67 & 5003.54 & 56.02 & 51.09 & 162435.33 & 2638846.97 & 1443.05 \\
\hline 云南 & 0.459 & -53.20 & -609.18 & -7.97 & -9.50 & 112458. 06 & 2488632.27 & 174.64 \\
\hline 广西 & 0.961 & -83.85 & -223.43 & -11.78 & -13.18 & 0 & 0 & 0 \\
\hline
\end{tabular}

通过对表5、表6中要素投入与产出调整情况进行研究, 以及对近 5 年被测DMU非DEA有效的相关松弛变量分析, 可 以看出, 在技术创新过程中, 基础资源投入不足, 投入转 化成果效率不高, 各地区资源投入与产出规模还不够合理, 产出效率不够高, 有效产出量贵乏是导致各地区非DEA有 效的主要原因。因此，提高各投入资源利用效率，增加有 效产出, 优化资源配置是提高 “一带一路” 沿线地区的技 术创新能力的关键。

\section{2. 基于Malmquist指数的 “一带一路” 沿线地区技术创} 新效率动态变化分析

从时间序列角度和省际角度分析中国 “一带一路” 沿 线地区技术创新效率的动态变化情况, 将基于Malmquist 指数的TFP引入技术创新效率研究, 把被测地区技术创新 效率的影响要素归结为综合技术效率和技术进步两个方 面, 并且结合DEA模型, 进一步分解综合技术效率为纯技 术效率和规模效率两个方面。 


\subsection{1. 基于时间序列的 TFP变动分析}

表7、表8是 “一带一路” 被测地区在技术知识产出阶段和技术商业化阶段各年度的TFP变化情况及分解特征。

表6 2010-2014年技术知识产出阶段TFP变动及分解特征。

\begin{tabular}{llllll}
\hline 年份 & 综合技术效率 $(E F c h)$ & 技术进步效率 $(T E c h)$ & 纯技术效率 $(P E c h)$ & 规模效率 $(S E c h)$ & 全要素生产率 $($ TFPch) \\
\hline $2010-2011$ & 0.950 & 1.106 & 0.986 & 0.964 & 1.051 \\
$2011-2012$ & 0.992 & 1.142 & 1.039 & 0.955 & 1.133 \\
$2012-2013$ & 1.077 & 0.969 & 1.036 & 1.040 & 1.044 \\
$2013-2014$ & 1.089 & 0.953 & 1.054 & 1.033 & 1.038 \\
平均值 & 1.026 & 1.039 & 1.029 & 0.997 & 1.066 \\
\hline
\end{tabular}

数据来源: 2011-2015年《中国科技统计年鉴》。

表7 2010-2014年技术商业化阶段TFP变动及分解特征。

\begin{tabular}{llllll}
\hline 年份 & 综合技术效率 $(E F c h)$ & 技术进步效率 $($ TEch $)$ & 纯技术效率 $(P E c h)$ & 规模效率 $(S E c h)$ & 全要素生产率 $($ TFPch $)$ \\
\hline $2010-2011$ & 0.972 & 1.334 & 0.972 & 1.000 & 1.296 \\
$2011-2012$ & 1.077 & 0.973 & 1.028 & 1.048 & 1.048 \\
$2012-2013$ & 0.995 & 1.116 & 1.010 & 0.985 & 1.110 \\
$2013-2014$ & 0.988 & 1.080 & 0.992 & 0.996 & 1.068 \\
平均值 & 1.007 & 1.119 & 1.000 & 1.007 & 1.127 \\
\hline
\end{tabular}

可以看出，2010-2014年技术创新全要素生产率TFP在 技术商业化阶段年均增长 (12.7\%) 高于在技术知识产出阶 段 (6.6\%)。从全要素生产率构成看, 技术知识产出阶段 综合技术效率年均增长 $2.6 \%$, 技术进步年均增长 $3.9 \%$, 技 术商业化阶段综合技术效率年均增长 $0.7 \%$ ，技术进步年均 增长 $11.9 \%$ ，表明技术进步对被测地区TFP增长的影响大于 综合技术效率的影响, 且在技术知识产出阶段综合技术效 率和技术进步对TFP影响的程度差距不大, 但在技术商业化 阶段, 技术进步对TFP的影响远大于综合技术效率的影响。

根 据上 式 $(4)$ 和 $(5)$, $T F P c h=E F c h \times T E c h=P E c h \times S E c h \times T E c h$

被测地区纯技术效率在技术知识产出阶段年均增长为 $2.9 \%$ ，在技术商业化阶段则没有增长，规模效率在技术知 识产出阶段和技术商业化阶段的年均变动分别为 $-0.3 \%$ 和
0.7\%，但同期技术进步效率的增长则分别是 $3.9 \%$ 和 $11.9 \%$, 说明被测地区技术创新的全要素生产率主要是由技术进步 推动的, 而综合技术效率的影响较小。值得注意的现象是 在技术知识产出阶段综合技术效率年均值增长 $2.6 \%$, 纯技 术效率年增长 $2.9 \%$, 但是在技术商业化阶段综合技术效率 年均增长仅有 $0.7 \%$, 纯技术效率年均维持不变。结合前文 相关DEA数据（表3、表4），综合技术效率和纯技术效率均 值在技术商业化阶段分别为 0.895 和 0.945 , 在技术知识产 出阶段分别为 0.709 和 0.807 , 提高被测地区综合技术效率 在技术知识产出阶段的潜力要大于技术商业化阶段。

\section{2. 2. 基于省际序列的TFP变动分析}

表9、表 10 是技术知识产出阶段和技术商业化阶段沿 线地区的TFP指数及分解特征。

表8 各地区在技术知识产出阶段TFP变动及分解特征。

\begin{tabular}{|c|c|c|c|c|c|c|}
\hline 地区 & & 综合技术效率 $(E F c h)$ & 技术进步效率 (TEch) & 纯技术效率 $(P E c h)$ & 规模效率 $(S E c h)$ & 全要素生产率 ( TFPch) \\
\hline \multirow{5}{*}{$\begin{array}{l}\text { 海 } \\
\text { 上 } \\
\text { 丝 } \\
\text { 路 }\end{array}$} & 上海 & 0.972 & 1.018 & 1.000 & 0.972 & 0.990 \\
\hline & 福建 & 0.993 & 1. 032 & 0.988 & 1. 004 & 1. 024 \\
\hline & 广东 & 0.942 & 1. 086 & 1. 000 & 0.942 & 1. 022 \\
\hline & 浙江 & 0.999 & 1. 047 & 1.000 & 0.999 & 1. 046 \\
\hline & 海南 & 0.984 & 1.045 & 1. 000 & 0.984 & 1. 029 \\
\hline \multirow{12}{*}{$\begin{array}{l}\text { 丝 } \\
\text { 绸 } \\
\text { 经 } \\
\text { 济 } \\
\text { 带 }\end{array}$} & 新疆 & 1. 064 & 1. 052 & 1. 080 & 0.984 & 1. 119 \\
\hline & 重庆 & 1. 000 & 1.085 & 1.000 & 1. 000 & 1. 085 \\
\hline & 陕西 & 1.000 & 1.030 & 1.000 & 1.000 & 1. 030 \\
\hline & 甘肃 & 0.979 & 0.995 & 1. 000 & 0.979 & 0.974 \\
\hline & 宁夏 & 1. 181 & 1. 029 & 1. 205 & 0.980 & 1.215 \\
\hline & 青海 & 1. 082 & 1. 051 & 1.000 & 1. 082 & 1. 137 \\
\hline & 内蒙古 & 1.006 & 1. 076 & 1.011 & 0.995 & 1. 083 \\
\hline & 黑龙江 & 1. 030 & 1. 034 & 1.000 & 1. 030 & 1. 065 \\
\hline & 吉林 & 1. 010 & 0.975 & 1. 000 & 1. 010 & 0.985 \\
\hline & 辽宁 & 1.002 & 1. 021 & 1. 003 & 0.999 & 1. 023 \\
\hline & 广西 & 1. 240 & 1. 030 & 1. 238 & 1. 002 & 1. 277 \\
\hline & 云南 & 0.993 & 1. 068 & 0.999 & 0.994 & 1. 061 \\
\hline 平均值 & & 1. 026 & 1. 039 & 1. 029 & 0.997 & 1. 066 \\
\hline
\end{tabular}


表9 各地区在技术商业化阶段TFP变动及分解特征。

\begin{tabular}{|c|c|c|c|c|c|c|}
\hline 地区 & & 综合技术效率 $(E F c h)$ & 技术进步效率 $(T E c h)$ & 纯技术效率 $(P E c h)$ & 规模效率 $(S E c h)$ & 全要素生产率 ( TFP $c h)$ \\
\hline \multirow{5}{*}{$\begin{array}{l}\text { 海 } \\
\text { 上 } \\
\text { 丝 } \\
\text { 路 }\end{array}$} & 上海 & 1.000 & 1.039 & 1.000 & 1.000 & 1.039 \\
\hline & 福建 & 0.966 & 1. 054 & 0.965 & 1.001 & 1. 019 \\
\hline & 广东 & 1.000 & 1. 035 & 1. 000 & 1. 000 & 1. 035 \\
\hline & 浙江 & 1. 071 & 1. 007 & 1. 023 & 1. 047 & 1. 078 \\
\hline & 海南 & 0.919 & 1. 108 & 0.934 & 0.984 & 1. 018 \\
\hline \multirow{12}{*}{$\begin{array}{l}\text { 丝 } \\
\text { 绸 } \\
\text { 经 } \\
\text { 济 } \\
\text { 带 }\end{array}$} & 新疆 & 1.008 & 1. 066 & 1.000 & 1.008 & 1.075 \\
\hline & 重庆 & 1.000 & 1. 014 & 1.000 & 1.000 & 1. 014 \\
\hline & 陕西 & 1.000 & 1. 289 & 1.000 & 1.000 & 1. 289 \\
\hline & 甘肃 & 1.000 & 1. 120 & 1.000 & 1.000 & 1. 120 \\
\hline & 宁夏 & 1.025 & 1. 094 & 1.000 & 1.025 & 1. 121 \\
\hline & 青海 & 1.000 & 1. 859 & 1. 000 & 1.000 & 1. 859 \\
\hline & 内蒙古 & 0.953 & 1. 077 & 0.958 & 0.995 & 1. 026 \\
\hline & 黑龙江 & 1. 053 & 1. 312 & 1.040 & 1. 013 & 1. 382 \\
\hline & 吉林 & 1.000 & 0.976 & 1.000 & 1.000 & 0.976 \\
\hline & 辽宁 & 1. 060 & 1. 058 & 1. 030 & 1. 029 & 1. 122 \\
\hline & 广西 & 0.996 & 1. 110 & 0.990 & 1. 006 & 1. 105 \\
\hline & 云南 & 1. 086 & 1. 030 & 1. 074 & 1. 011 & 1. 119 \\
\hline 平均值 & & 1. 007 & 1. 119 & 1.000 & 1. 007 & 1. 127 \\
\hline
\end{tabular}

从综合技术效率指数看, 在技术知识产出阶段, “海 上丝路” 沿线 5 省（市）均低于 “一带一路” 沿线地区均 值, 且都小于 1 ; 在技术商业化阶段, 除浙江外其余 4 省 (市) 也都低于 “一带一路” 沿线地区均值, 表明 “海上丝路” 沿线5省（市）综合技术效率增速低于 “丝绸经济带” 地 区, 且近 5 年有不同程度负增长。从技术进步效率指数看, 在技术知识产出阶段 “海上丝路”沿线5省 (市) 都大于 1 , 且除上海和广东外其余3省都高于 “一带一路” 沿线地区 均值; 在技术商业化阶段, “海上丝路” 沿线5省（市） 都大于 1 , 但都低于 “一带一路” 沿线地区均值, 表明 “海 上丝路” 沿线 5 省 (市) 技术是进步的, 且在知识产出阶 段技术进步指数高于 “丝绸经济带” 沿线地区, 在商业化 阶段技术进步指数低于 “丝绸经济带” 沿线地区。从全要 素生产率看, “丝绸经济带” 沿线在技术知识产出阶段, 广西、青海、宁夏、新疆的TFP指数增长幅度分别达到了 $27.7 \% 、 13.7 \% 、 21.5 \%$ 和 $11.9 \%$; 在技术商业化阶段, 丝绸 经济带” 沿线的陕西、黑龙江的TFP增长幅度分别为 $28.9 \%$ 和 $38.2 \%$, 青海的TFP增长更是高达 $85.9 \%$ 。“海上丝路” 沿线 5 省（市）在技术知识产出阶段和技术商业化阶段的 TFP增长率都低于 “一带一路” 沿线地区均值。充分说明 “一带一路” 沿线地区全要素生产率增长主要依靠 “丝绸 经济带” 沿线地区, 且 “丝绸经济带” 沿线地区的TFP增 长趋势良好、潜力较大。

\section{5. 结论}

本文利用DEA和Malmquist指数法, 对我国 “一带一路” 沿线地区2010-2014年技术创新效率的动态和静态变化进 行分析, 得出以下主要结论:

（1）我国 “一带一路” 沿线地区综合技术效率水平 在技术商业化阶段较高, 在技术知识产出阶段偏低, 纯技 术效率和综合技术效率都有一定的提升空间, 规模效率是 制约“海上丝路”沿线地区综合技术效率提高的主要原因,
纯技术效率是制约 “丝绸经济带”沿线地区综合技术效率 提高的主要因素。

（2）我国 “丝绸经济带” 沿线地区大部分处于规模 效率递增状态, “海上丝路” 沿线地区大部分处于规模效 率不变和规模递减状态, 表明 “丝绸经济带” 沿线地区同 比例加大相关要素投入可以得到更多产出, 而 “海上丝路” 沿线地区投入规模应保持不变和适当缩减，同时提高资源 利用效率, 优化资源配置, 增加有效产出。

（3）我国 “一带一路” 沿线地区基于动态角度的TFP 指数处于增长态势。在技术商业化阶段, TFP增长的主要 原因是技术进步的增长; 在技术知识产出阶段, 技术进步 与综合技术效率的提高对TFP的增长都有重要的影响。

根据本文分析及上述结论, 实施 “一带一路” 战略, 提升并巩固我国在 “一带一路” 沿线国家经济技术发展互 动中的主动地位, 必须从政府、企业和科研机构三方面采 取有效措施，努力提高我国沿线地区技术创新能力。

（1）我国 “一带一路” 沿线省（区、市）政府要有 效发挥调控和导向作用, 强化政策支持, 优化创新环境, 创新人才和技术引进制度, 加强省际合作和优势互补。技 术创新效率低但增长潜力大的新疆、宁夏、青海、广西等 省区, 一方面, 要进一步加大政策支持力度, 采取灵活多 样的管理机制, 努力吸纳科技人才; 另一方面, 要进一步 加大 R\&D投入力度, 提升科技基础实力; 第三, 要进一步 改善创新创业和投资环境, 有效吸收外部技术、企业和资 本。

（2）企业是技术创新的主体，我国 “一带一路” 沿 线企业要努力改善投入产出规模和结构, 规模以上企业及 高技术企业要加大技术改造、提升和引进力度, 从根本上 提高沿线地区技术创新效率和使用效率。“海上丝路”沿 线地区及规模效率较低且TFP增长缓慢的企业, 要积极调 整和控制研发投入，优化投入产出结构; “丝䀦经济带” 沿线地区及纯技术效率较低但TFP增长明显的企业, 要进 一步加大技术创新资源投入, 扩大规模, 争取更大收益。 
（3）我国 “一带一路” 沿线地区科研院所和高等院 校, 要努力提高科技研发效率, 增加研发经费和人员投入, 积极开展协同创新, 加强与企业的联合与合作，提高科技 成果产业化能力和商业价值转化效率。

\section{致谢}

本文为陕西省软科学研究计划重点项目《科技支撑 “丝绸之路经济带” (陕西) 发展对策研究》(2015KRZ001) 的阶段性成果之一。

\section{参考文献}

[1] 刘卫东. “一带一路” 战略的科学内涵与科学问题 $[J]$. 地 理科学进展, 2015 (05) : 538-544。

２］吴建南，杨若愚. 中国与 “一带一路” 国家的科技合作态 势研究 $[J]$. 科学学与科学技术管理, 2016 (01) : 14-19。

［3］孔庆峰、董虹蔚. 一带一路” 国家的贸易便利化水平测算 与贸易潜力研究 $[J]$. 国际贸易问题, 2015(12) : 158-168。

［4］杨广青、杜海鹏. 人民币汇率变动对我国出口贸易的影响 一基于 “一带一路” 沿线79个国家和地区面板数据的研究 [J]. 经济学家, 2015(11)：43-50。

［5］张良卫. “一带一路” 战略下的国际贸易与国际物流协同 分析一以广东省为例 $[J]$. 财经科学, 2015(07)：81-88。
［6］陈恒、魏修建. “一带一路” 物流业发展驱动因素的动态 轨迹演变一基于劳动力投入的视角 $[\mathrm{J}]$. 上海财经大学学报, 2015 (02) : 31-42。

[7] Jooh Lee\&Eunsup Shim. Moderating effects of R\&D on corporate growth in U. S. and Japanese hi-tech industries: an empirical study $[\mathrm{J}]$. The Journal of High Technology Management Research, 1995 (6) :179191.

[8] Romijn H, Mike A. Innovation, networking and proximity: lessons from small high technology firms in the UK [J]. Regional Studies, 2002, 36(1):81-86.

[9] Neelankavil J. P, Alaganar V. T. Strategic resource commitment of high technology firms an international comparison $[\mathrm{J}]$. Journal of Business Research, $2003(6): 493-502$.

[10］赵树宽、余海晴、巩顺龙. 基于DEA方法的吉林省高技术企 业创新效率研究 $[J]$ 。科研管理, 2013 (02)：36-43。

[11] 熊婵、买忆媛、何晓斌. 基于DEA方法的中国高科技创业企 业运营效率研究 $[J]$ 。管理科学, 2014(02)：26-37。

[12] Maria A. The evaluation of regional innovation and cluster policies: looking for new approaches $[\mathrm{J}]$. In Decentralization and Evaluation, 2000 (4) : 276-315。

[13] 郭军华、倪明. 基于非参数HMB指数法的区域创新效率变动 分析 $[J]$ 。管理学报, 2011 (01) :137-142。

[14] 官建成, 陈凯华. 我国高技术产业技术创新效率的测度 [J]．数量经济技术经济研究, 2009 (10) : 19-33。

[15] 魏权龄. 数据包络分析 [M] 北京: 科学出版社, 2004 。 